\title{
Effect of artificially accelerated aging on margin fit and color stability of laminate veneers
}

\author{
Tamer A. Hamza', Mohammed A. Al-Baili, ${ }^{2,3}$, Mohamed H. Abdel-Aziz² \\ 'Faculty of Oral and Dental Medicine, Misr International University, Cairo 11828, Egypt. \\ ${ }^{2}$ Faculty of Dental Medicine, Al-Azhar University, Cairo 11651, Egypt. \\ ${ }^{3}$ Faculty of Dental Medicine, Sanaa University, Sanaa 11371, Yemen.
}

Correspondence to: Prof. Tamer A. Hamza, Faculty of Oral and Dental Medicine, Misr International University, Cairo 11828, Egypt. E-mail: drtamerhamza@hotmail.com

\begin{abstract}
How to cite this article: Hamza TA, Al-Baili MA, Abdel-Aziz MH. Effect of artificially accelerated aging on margin fit and color stability
\end{abstract} of laminate veneers. Stomatological Dis Sci2018;2:1. http://dx.doi.org/10.20517/2573-0002.2017.09

Received: 28 May 2017 First Decision: 8 Jan 2018 Revised: 17 Jan 2018 Accepted: 26 Jan 2018 Published: 31 Jan 2018

Science Editor: Nikolaos G. Nikitakis Language Editor: Jun-Yao Li Electronic Editor: Huan-Liang Wu

\begin{abstract}
Aim: The purpose of the study was to evaluate the effect of artificially accelerated aging on marginal fit and color stability of three CAD/CAM materials used to fabricate laminate veneers.
\end{abstract}

Methods: A typodont maxillary central incisor tooth was prepared to receive a ceramic veneer, then duplicated to create 15 epoxy resin teeth equally divided into three groups according to the ceramic used to fabricate laminate veneers. Three groups were established: Group (N) nano-hybrid ceramic (Lava ${ }^{\mathrm{TM}}$ Ultimate; 3M ESPE); Group (L) CAD/CAM lithium disilicate glass ceramic block (IPS e.max ${ }^{\circledR}$ CAD; Ivoclar Vivadent); and Group (F) leucite-reinforced glass ceramic block (IPS Empress ${ }^{\circledR}$ CAD; Ivoclar Vivadent). All of the specimens were subjected to artificial aging using a weathering process in a Weather-O-meter for $300 \mathrm{~h}$. Margin fit and color measurements were carried out before and after artificial aging of the laminates.

Results: The results for the marginal fit revealed that there was no statistically significant difference between the mean marginal gap distance of the aged and non-aged specimens in the nano-hybrid ceramic. However, lithium disilicate glass ceramic and leucite-reinforced glass ceramic blocks showed a statistically significant change in the marginal gap. For color measurement, Lava ${ }^{\mathrm{TM}}$ Ultimate demonstrated a significant decrease in $\left(a^{\star}\right)$ value while the $\left(\mathrm{L}^{\star}\right)$ and $\left(b^{\star}\right)$ values did not show a statistically significant change.

Conclusion: Within the limitation of this study, it can be concluded that aging the nano-hybrid ceramic had a superior marginal fit and inferior color stability.

Keywords: e.max ${ }^{\oplus}$, hybrid ceramics, ceramics, color stability, veneers

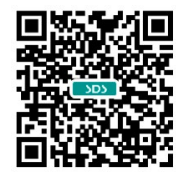




\section{INTRODUCTION}

Patients' awareness and demand for aesthetic restorations that mimic the look of natural teeth is everincreasing and has become one of the patients' primary concerns ${ }^{[1,2]}$. Although bleaching is considered the most conservative approach to achieving such goals, in other cases, bleaching cannot solve other issues. This is true when the teeth have minor defects or severally discolored teeth. Ceramic veneers are another conservative solution for anterior teeth in clinical situations that include cases of severe discoloration, enamel defects, diastema, malpositioned or fractured teeth, and aging ${ }^{[3]}$. There are different materials and techniques which can be used for the construction of ceramic veneers which differ from case to case and according to the clinical situation. Clinicians seek products that are characterized by durability and functional stability. CAD/CAM manufactured ceramic veneering materials including leucite ${ }^{[4]}$, lithium disilicate $^{[5,6]}$ and resin nano-ceramics can be utilized. The latter product is composed of a blend of fillers embedded in a fully cured highly cross-linked resin matrix ${ }^{[7,8]}$. The resin content of this material (19\% by weight) renders it more resilient which reduces the time needed to fabricate the final dental prosthesis ${ }^{[9,10]}$.

Ceramic veneers resemble the natural teeth color. It is important that this color remains unchanged during service. A recent study by Acar et al. ${ }^{[11]}$ compared four types of veneers after thermocycling in coffee. The lithium disilicate was most stable without significant color changes. The hybrid ceramic showed a color change that was clinically acceptable while nano-ceramic and nano-composite were not. The color change is evaluated by the calibrated color difference $(\Delta \mathrm{E})$, which has values for perceptible and clinically acceptable $(\Delta \mathrm{E}<3.7)^{[12]}$ results.

A proper marginal fit is vital to prevent potential space between the external margin of restoration and the prepared teeth. Otherwise, complications that include dissolution of the luting cement, plaque accumulation with subsequent gingival inflammation, caries, pulpal involvement, and the creation of stress concentrations (which may reduce the strength of the restoration with subsequent fracture ${ }^{[13]}$ ) may result. The most widely accepted clinical marginal opening ranges from 40 to $120 \mu \mathrm{m}^{[14,15]}$.

Lin et al. ${ }^{[16]}$ compared the marginal gap between different types of ceramic veneers; leucite-reinforced ceramic and conventional sintered feldspathic porcelain. They found that no statistically significant difference was found between the ceramic types. Aboushelib et al. ${ }^{[17]}$ compared the marginal gap of pressable and machinable ceramic veneers. They found that pressable ceramic veneers show lower marginal fit values.

The effect of the oral environment on the performance of various types of veneer materials should be investigated to provide patients with veneers that last longer. Long-term stability is influenced by the oral cavity conditions (such as temperature and $\mathrm{pH}$ changes, humidity) and the ability of the veneer material to withstand these conditions ${ }^{[18,19]}$.

Artificially accelerated aging is used to simulate the oral environmental conditions to evaluate the ability of restorative materials to remain unchanged ${ }^{[20-22]}$.

There is limited published data on the clinical performance of ceramic veneers under the effect of aging using artificially accelerated aging, and to our knowledge no known published data. Therefore, the objective of this study was to evaluate the effect of aging on the color and marginal fit of three types of CAD/CAM manufactured laminate veneers. The null hypothesis of this study was that the artificial aging would not affect the margin fit and color stability of ceramic veneers.

\section{METHODS}

A power analysis was performed using Epi Info ${ }^{\mathrm{ma}}$ v6 (US Centers for Disease Control and Prevention) to calculate the sample size, guided by the power of the test, $80 \%$, and the accepted margin of error, $5 \%$. For 


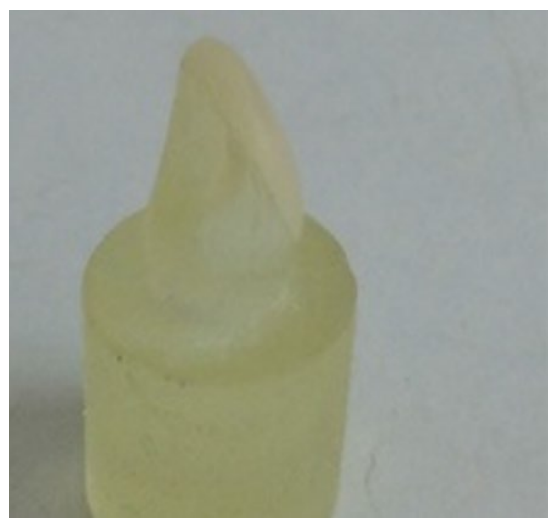

Figure 1. laminate veneer after cementation

alpha level, $\beta=0.20$ for the power of $80 \%$. The effect size calculation was based on the study of Bagis and Turgut $^{[23]}$. After the calculation, the predicted number was five specimens in each group.

A typodont maxillary central incisor tooth was prepared to receive a ceramic veneer. A labial preparation depth was $0.5 \mathrm{~mm}$ and a butt-joint $2 \mathrm{~mm}$ incisal reduction. It was then duplicated to create 15 epoxy resin teeth $^{[24]}$ equally divided into three groups to receive three types of laminate veneers. Group $(\mathrm{N})$ nanohybrid ceramic (Lava ${ }^{\text {Tm }}$ Ultimate; 3M ESPE), Group (L) CAD/CAM lithium disilicate glass ceramic block (IPS e.max ${ }^{\circ}$ CAD; Ivoclar Vivadent), and Group (F) leucite-reinforced glass ceramic block (IPS Empress ${ }^{\circ}$ CAD; Ivoclar Vivadent) [Figure 1] were selected.

Each prepared die was scanned using in-lab software version 3.8. The ceramic blocks were then milled using a CAD/CAM milling machine (In-lab MC XL milling machine). The laminate veneers were seated and cemented with a self-adhesive universal resin cement (Rely $\mathrm{X}^{\mathrm{m}}$ Unicem $3 \mathrm{M}$ ), on the prepared dies using a loading device with a fixed pressure of $250 \mathrm{~g}$ applied for $1 \mathrm{~min}^{[17]}$. The marginal fit of laminate veneer was evaluated by measuring the gap between the edge of the laminate and the finish line in a vertical direction using a USB Digital microscope at a fixed magnification of 90x. A digital image analysis system (ImageJ $1.43 \mathrm{U}$, National Institute of Health, USA) was used to measure and qualitatively evaluate the gap width. The color was measured using a spectrophotometer (X-Rite, model RM200QC, Neu-Isenburg, Germany). The aperture size was set to $4 \mathrm{~mm}$, and the specimens were exactly aligned with the device. Measurements were made according to the CIE $\left(\mathrm{L}^{*} \mathrm{a}^{*} \mathrm{~b}^{*}\right)$ color space relative to the CIE standard illuminant D65. To artificially age the specimens, a weathering machine called environmental incubator model (Jeio Tech TEMI 300, South Korea) was used. The weathering process involved ultraviolet irradiation, fluctuant temperatures, and a controlled humid atmosphere. All of the specimens were placed on the equipment shelf and exposed to a 9 UV-B light source with radiation of $280 / 320 \mathrm{~nm}$, at a distance of $50 \mathrm{~nm}$, in the condensation chamber. The program was set for $4 \mathrm{~h}$ of UV-B exposure at $50{ }^{\circ} \mathrm{C}$, and $4 \mathrm{~h}$ of condensation for a maximum of 300 $\mathrm{h}$, equivalent to 1 year of clinical service ${ }^{[25,26]}$. All specimens underwent the same color and marginal gap measurements as before the artificially accelerated aging process.

The color difference $(\Delta \mathrm{E})$ values were evaluated by calculating the difference in color measurements of the specimens before and after the artificially accelerated aging by using the following formula:

$\Delta \mathrm{E}\left(\mathrm{L}^{\star} \mathrm{a}^{\star} \mathrm{b}^{\star}\right)=\left[\left(\mathrm{L}^{\star}{ }_{1}-\mathrm{L}^{\star} 2\right)^{2}+\left(\mathrm{a}^{*}{ }_{1}-\mathrm{a}_{2}\right)^{2}+\left(\mathrm{b}^{*}{ }_{1}-\mathrm{b}_{2}{ }_{2}\right)^{2}\right]^{1 / 2}$

Where numbers "1" and "2" refer to the color coordinates before and after the artificially accelerated aging respectively; $\left(\mathrm{L}^{*}\right)=$ lightness $(0-100),\left(\mathrm{a}^{*}\right)=($ change the color of the axis red/green $)$ and $\left(\mathrm{b}^{\star}\right)=($ color variation axis yellow/blue $)^{[27,28]}$. 
Table 1. Results of comparison between marginal gap distance of aged and non-aged specimens

\begin{tabular}{|c|c|c|c|c|c|}
\hline \multirow{2}{*}{ Ceramic type } & \multicolumn{2}{|c|}{ Aged } & \multicolumn{2}{|c|}{ Non-aged } & \multirow{2}{*}{$P$ value } \\
\hline & Mean & SD & Mean & SD & \\
\hline Lava Ultimate & 85.3 & 24.1 & 62.0 & 22.6 & 0.117 \\
\hline IPS e.max ${ }^{\circledR}$ & 84.4 & 5.4 & 52.9 & 17.7 & $0.009^{*}$ \\
\hline IPS Empress & 89.4 & 12.3 & 61.6 & 7.2 & $0.009^{*}$ \\
\hline
\end{tabular}

*Significant at $P \leq 0.05$

\section{Statistical analysis}

Numerical data were explored for normality by checking the data distribution, calculating the mean and median values and using Kolmogorov-Smirnov and Shapiro-Wilk tests. All data showed non-parametric distribution except for $\left(\mathrm{L}^{\star}\right)$ color parameter which showed parametric distribution. Data were represented by mean and standard deviation (SD) values. The Kruskal-Wallis test was used to compare the three ceramic types. The Mann-Whitney $U$ test was used to compare between aged and non-aged specimens. A Paired $t$-test was used to compare between $\left(L^{*}\right)$ values before and after aging. The Wilcoxon signed-rank test was used to compare between $\left(\mathrm{a}^{*}\right)$ and $\left(\mathrm{b}^{*}\right)$ values before and after aging. The significance level was set at $P \leq 0.05$. Statistical analysis was performed with an IBM (IBM Corporation, NY, USA) SPSS (SPSS, Inc., an IBM Company) Statistics Version 20 for Windows.

\section{RESULTS}

The results for the marginal gap [Table 1] revealed that there was no statistically significant difference between mean marginal gap distance of aged and non-aged specimens in the Lava ${ }^{\mathrm{m}}$ Ultimate group. However, IPS e. $\max ^{\oplus}$ and IPS Empress ${ }^{\circledR}$ groups showed a statistically significant change in the marginal gap under the effect of aging as the age group showed a higher mean marginal gap distance than the non-aged group. The mean and the standard deviation of the CAD/CAM lithium disilicate IPS e.max ${ }^{\bullet}$ before aging was $52.9 \pm 17.7$, and after aging was $84.4 \pm 5.4$, The IPS Empress ${ }^{\bullet}$ leucite-reinforced glass ceramic before aging was $61.6 \pm 7.2$, and after aging was $89.4 \pm 12.3$. The nano-hybrid ceramic Lava ${ }^{\mathrm{m}}$ Ultimate before aging was $62.0 \pm 22.6$, and after aging was $85.3 \pm 24.1$.

The results of the effect of aging on color parameters are presented in Table 2. Mean and SD values for each group were computed before and after aging. Lava ${ }^{\text {Tw }}$ Ultimate demonstrated a significant decrease in $\left(a^{*}\right)$ value while the $\left(L^{*}\right)$ and the $\left(b^{*}\right)$ values did not show a statistically significant change. The CAD/ CAM lithium disilicate IPS e.max ${ }^{\star}$ as well as the IPS Empress ${ }^{\star}$ leucite-reinforced glass ceramic, there was no statistically significant change in $\left(L^{*}\right),\left(a^{*}\right)$ as well as $\left(b^{*}\right)$ values after aging. There was no statistically significant difference between color changes of the three ceramic types when they were compared.

\section{DISCUSSION}

The null hypothesis of this study was rejected. There was a significant difference between the color properties and the marginal gap of the ceramic veneer materials tested. In the present study, highly filled epoxy resin teeth were used as replicas of natural teeth since they have a modulus of elasticity similar to that of human dentin $(14.7 \mathrm{GPa})^{[24]}$. Other studies used human teeth, bovine, or animal teeth ${ }^{[18,19]}$. The human teeth are affected by variables caused by differences in the surface characteristics (cracks, attrition, wear), age of the extracted teeth and the storage after extraction (distilled water, saline, dry storage) ${ }^{[29]}$.

The butt-joint preparation design used in the current study enabled a thicker ceramic layer at the incisal edge of the laminate veneer that increased the translucency of the restoration ${ }^{[30]}$. 
Table 2. Results of comparison between $L^{\star}, a^{\star}$ and $b^{\star}$ parameters before and after aging with each ceramic type

\begin{tabular}{|c|c|c|c|c|c|c|}
\hline \multirow{2}{*}{ Ceramic type } & \multirow{2}{*}{ Color parameters } & \multicolumn{2}{|c|}{ Before aging } & \multicolumn{2}{|c|}{ After aging } & \multirow{2}{*}{$P$ value } \\
\hline & & Mean & SD & Mean & SD & \\
\hline \multirow[t]{3}{*}{ Lava Ultimate } & $L^{*}$ & 59.32 & 3.59 & 58.94 & 4.07 & 0.736 \\
\hline & $a^{\star}$ & -0.70 & 0.14 & -1.42 & 0.56 & $0.042^{\star}$ \\
\hline & $b^{\star}$ & 3.30 & 0.00 & 5.24 & 2.29 & 0.138 \\
\hline \multirow[t]{3}{*}{ IPS e.max } & $L^{*}$ & 65.24 & 3.89 & 62.18 & 5.51 & 0.096 \\
\hline & $a^{\star}$ & -0.88 & 0.77 & -0.50 & 0.89 & 0.345 \\
\hline & $b^{\star}$ & 11.36 & 2.82 & 10.14 & 2.77 & 0.223 \\
\hline \multirow[t]{3}{*}{ IPS Empress } & $L^{*}$ & 59.30 & 1.40 & 58.66 & 3.71 & 0.686 \\
\hline & $a^{\star}$ & -0.40 & 0.53 & -0.70 & 0.74 & 0.684 \\
\hline & $b^{*}$ & 8.90 & 1.17 & 7.94 & 2.48 & 0.345 \\
\hline
\end{tabular}

*Significant at $P \leq 0.05$

The materials used in this study included IPS Empress ${ }^{\circledR} \mathrm{CAD}$ which was chosen as it is the ideal material for veneers featuring a natural appearance in shade, translucency, and fluorescence ${ }^{[4]}$. IPS e-max ${ }^{\otimes} \mathrm{CAD}$ was also chosen for its unique combination of compression strength $(360 \mathrm{Mpa})$, and aesthetic properties ${ }^{[5,6]}$. Lava $^{\mathrm{m}}$ Ultimate represents a relatively new category of resin nano-ceramics. Seating of the veneers using a standardized technique was adopted. Other studies used finger pressure technique which does not ensure standardization $^{[18]}$.

In this study, artificially accelerated aging is a method to simulate intraoral conditions. According to the manufacturer, $300 \mathrm{~h}$ of weathering equals one year of clinical intraoral service ${ }^{[26]}$. Weathering is a convenient method to test the performance and endurance of dental materials used in many studies ${ }^{[22,26]}$. It encompasses alternating exposure of darkness and light as well as intermittent exposure to water spray. Validation of the method was verified by previous studies ${ }^{[20,25,26]}$.

Regarding the color difference, the $\Delta \mathrm{E}$ mean values showed no statistically significant differences between the three tested groups; whereas, the mean and standard deviation of the IPS e.max ${ }^{\odot}$ CAD showed the highest mean value followed by the IPS Empress ${ }^{\circ}$ CAD and the Lava ${ }^{\mathrm{m}}$ Ultimate showed the lowest mean value. This result is not in agreement with Acar et al. ${ }^{[11]}$ who stated that lithium disilicate was the most color stable material compared to hybrid nano-ceramic and nano-composite. The difference may be attributed to the method of aging. The latter used coffee thermocycling which includes temperature fluctuation, and coffee staining. The incubator used in this study included ultraviolet radiation, humidity, and temperature fluctuation.

In the current study, Lava ${ }^{\mathrm{Tm}}$ Ultimate and IPS Empress ${ }^{\circledR} \mathrm{CAD}$ the $\triangle \mathrm{E}$ mean values were perceptible but clinically acceptable $(\Delta \mathrm{E}<3.7)$ which were deemed non-acceptable in the study of Acar et al. ${ }^{[11]}$. However, IPS e.max ${ }^{\oplus} \mathrm{CAD}$ was perceptible and clinically non-acceptable $(\Delta \mathrm{E}>3.7)$ a result that did not agree with Acar et al. ${ }^{[1]}$ who stated that it was non-perceptible.

Under the effect of aging, the Lava ${ }^{\mathrm{Tw}}$ Ultimate demonstrated a decrease in the $\left(\mathrm{a}^{*}\right)$ value. The IPS e.max ${ }^{\star}$ and IPS Empress ${ }^{\circledR}$ were not affected by aging. Previous studies evaluating color characteristics revealed different findings. Turgut and Bagis ${ }^{[20]}$ stated that aging caused significant color changes in ceramic discs made of IPS e.max ${ }^{\circ}$ press luted with three types of luting agents, one of which is the type used in the current study $\left(\operatorname{RelyX} \mathrm{X}^{\mathrm{m}}\right)$. The $\left(\mathrm{L}^{\star}\right)$ and $\left(\mathrm{a}^{*}\right)$ values decreased while the $\left(\mathrm{b}^{*}\right)$ value increased after aging. In the current study, the only value that changed was a decrease in the $\left(\mathrm{a}^{\star}\right)$ value in the Lava ${ }^{\mathrm{m}}$ Ultimate. This difference may be attributed to the difference in the material used.

Regarding the marginal gap, all of the tested materials demonstrated an acceptable value. The acceptable clinical marginal opening is between 40 and $120 \mathrm{um}^{[14,15]}$. There was no significant difference found between the three ceramic types before and after aging which is similar to findings of other studies ${ }^{[16,17]}$. 
After the artificially accelerated aging, IPS e.max ${ }^{\star}$ and IP Empress ${ }^{\circledR}$ demonstrated a significant increase in the marginal gap compared to the pre-aging values. However, the Lava ${ }^{\mathrm{Tx}}$ Ultimate group did not reveal any significant change in the marginal gap under the effect of aging. This lack of significance may be attributed to the resin component in the Lava ${ }^{\text {tm }}$ Ultimate and in the epoxy resin die material.

In conclusion, within the limitation of this study, it can be concluded that by aging the nano-hybrid ceramic had a superior marginal fit and inferior color stability.

\section{DECLARATIONS}

\section{Acknowledgments}

The author would like to acknowledge the efforts of Dr. Jon Wanger in refining the final manuscript.

\section{Authors' contributions}

Idea, planning and supervising in practical and final writing: Hamza TA

Practical and initial writing: Al-Baili MA

Final writing: Abdel-Aziz MH

\section{Data source and availability}

All data are stored in the computer lab in faulty of dental medicine Azhar university.

\section{Financial support and sponsorship}

None.

\section{Conflicts of interest}

There are no conflicts of interest.

\section{Patient consent}

Not applicable.

\section{Ethics approval}

Not applicable.

\section{Copyright}

(c) The Author(s) 2018.

\section{REFERENCES}

1. Spyropoulou PE, Giroux EC, Razzoog ME, Duff RE. Translucency of shaded zirconia core material. J Prosthet Dent 2011;105:304-7.

2. Aktas G, Sahin E, Vallittu P, Ozcan M, Lassila L. Effect of colouring green stage zirconia on the adhesion of veneering ceramics with different thermal expansion coefficients. Int J Oral Sci 2013;5:236-41.

3. Mathew C, Ks S. A review on ceramic laminate veneers. J Indian Acad Dent Spec 2010;1:33-7.

4. Charlton DG, Roberts HW, Tiba A. Measurement of select physical and mechanical properties of 3 machinable ceramic materials. Quintessence 2008;39:573-9.

5. Yeo IS, Yang JH, Lee JB. In vitro marginal fit of three all-ceramic crown systems. J Prosthet Dent 2003;90:459-64.

6. Mansour YF, AL-Omiri MK, Khader YS, Al-Wahadni AM. Clinical performance of IPS-Empress 2 ceramic crowns inserted by general dental practitioners. J Contemp Dent 2008;9:9-16.

7. Bilkhair A. Fatigue behaviour and failure modes of monolithic CAD/CAM hybrid-ceramic and all-ceramic posterior crown restorations. Available from: https://www.google.com.hk/url?sa=t\&rct=j\&q=\&esrc=s\&source=web\&cd=1\&ved=0ahUKEwi8k-7e6_TYAhVPv5QKH ZKpDPYQFgglMAA\&url=\%68\%74\%74\%70\%73\%3a\% $\% 2 \mathrm{f} \% 2 \mathrm{f} \% 66 \% 72 \% 65 \% 69 \% 64 \% 6 \mathrm{f} \% 6 \mathrm{~b} \% 2 \mathrm{e} \% 75 \% 6 \mathrm{e} \% 69 \% 2 \mathrm{~d} \% 66 \% 72 \% 65 \% 69$ $\% 62 \% 75 \% 72 \% 67 \% 2 \mathrm{e} \% 64 \% 65 \% 2 \mathrm{f} \% 64 \% 6 \mathrm{e} \% 62 \% 2 \mathrm{f} \% 64 \% 6 \mathrm{f} \% 77 \% 6 \mathrm{e} \% 6 \mathrm{c} \% 6 \mathrm{f} \% 61 \% 64 \% 2 \mathrm{f} \% 39 \% 33 \% 36 \% 33 \&$ usg=AOvVaw0yORaH M5F4ImNON6dIpf5e [Last accessed on 26 Jan 2018]

8. Volpato CÂM, Bondioli F, Altoé Garbelotto LGD, Fredel MC. Application of zirconia in dentistry: biological, mechanical and optical 
considerations. INTECH Open Access Publisher; 2011.

9. Özcan M, Jonasch M. Effect of cyclic fatigue tests on aging and their translational implications for survival of all-ceramic tooth-borne single crowns and fixed dental prostheses. J Prosthodont 2016; doi: 10.1111/jopr.12566.

10. Lee YK, Lu H, Powers JM. Changes in opalescence and fluorescence properties of resin composites after accelerated aging. Dent Mater 2006;22:653-60.

11. Acar O, Yilmaz B, Altintas SH, Chandrasekaran I, Johnston WM. Color stainability of CAD/CAM and nanocomposite resin materials. $J$ Prosthet Dent 2016;115:71-5.

12. Sahin V, Uludag B, Usumez A, Ozkir SE. The effect of repeated firings on the color of an alumina ceramic system with two different veneering porcelain shades. $J$ Prosthet Dent 2010;104:372-8.

13. Conrad HJ, Seong WJ, Pesun IJ. Current ceramic materials and systems with clinical recommendations: a systematic review. $J$ Prosthet Dent 2007;98:389-404.

14. Boyle JJ Jr, Naylor WP, Blackman RB. Marginal accuracy of metal ceramic restorations with porcelain facial margins. J Prosthet Dent 1993;69:19-27.

15. McLean JW, von Fraunhofer JA. The estimation of cement film thickness by an in vivo technique. Br Dent J 1971;131:107-11.

16. Lin TM, Liu PR, Ramp LC, Essig ME, Givan DA, Pan YH. Fracture resistance and marginal discrepancy of porcelain laminate veneers influenced by preparation design and restorative material in vitro. $J$ Dent 2012;40:202-9.

17. Aboushelib MN, Elmahy WA, Ghazy MH. Internal adaptation, marginal accuracy and microleakage of a pressable versus a machinable ceramic laminate veneers. $J$ Dent 2012;40:670-7.

18. Zarone F, Epifania E, Leone G, Sorrentino R, Ferrari M. Dynamometric assessment of the mechanical resistance of porcelain veneers related to tooth preparation: A comparison between two techniques. J Prosthet Dent 2006;95:354-63.

19. Kelly JR, Nishimura I, Campbell SD. Ceramics in dentistry: historical roots and current perspectives. J Prosthet Dent 1996;75:718-32.

20. Turgut S, Bagis B. Colour stability of laminate veneers: an in vitro study. J Dent 2011;39 Suppl 3:e57-64.

21. Atay A, Oruç S, Ozen J, Sipahi C. Effect of accelerated aging on the color stability of feldspathic ceramic treated with various surface treatments. Quintessence Int 2008;39:603-9.

22. Nikzad S, Azari A, Poursina M. Effects of beverage colorants and accelerated aging on the color stability of indirect resin composites. $J$ Dent Sci 2012;7:231-7.

23. Bagis B, Turgut S. Optical properties of current ceramics systems for laminate veneers. J Dent 2013;41 Suppl 3:e24-30.

24. Pallis K, Griggs JA, Woody RD, Guillen GE, Miller AW. Fracture resistance of three all-ceramic restorative systems for posterior applications. J Prosthet Dent 2004;91:561-9.

25. Heydecke G, Zhang F, Razzoog ME. In vitro color stability of double-layer veneers after accelerated aging. J Prosthet Dent 2001;85:551-7.

26. Paravina RD, Ontiveros JC, Powers JM. Accelerated aging effects on color and translucency of bleaching-shade composites. $J$ Esthet Restor Dent 2004;16:117-26; discussion 126-7.

27. Chaiyabutr Y, Kois JC, LeBeau D, Nunokawa G. Effect of abutment tooth color, cement color, and ceramic thickness on the resulting optical color of a CAD/CAM glass-ceramic lithium disilicate-reinforced crown. J Prosthet Dent 2011;105:83-90.

28. Alghazali N, Burnside G, Moallem M, Smith P, Preston A, Jarad FD. Assessment of perceptibility and acceptability of color difference of denture teeth. $J$ Dent 2012;40 Suppl 1:e10-7.

29. Potiket N, Chiche G, Finger IM. In vitro fracture strength of teeth restored with different all-ceramic crown systems. J Prosthet Dent 2004; $92: 491-5$.

30. Guess PC, Stappert CFJ. Midterm results of a 5-year prospective clinical investigation of extended ceramic veneers. Dent Mater 2008;24:804-13. 